\title{
Systems Integration for Manufacturing Applications Technical Program Plan
}

An intramural NIST research and standards development program applying High Performance Computing and Communications technology to manufacturing applications.

James E. Fowler

U.S. DEPARTMENT OF COMMERCE Technology Administration National Institute of Standards and Technology

Manufacturing Engineering Laboratory Manufacturing Systems Integration Division Gaithersburg, MD 20899-0001

QC 



\section{Systems Integration for \\ Manufacturing Applications \\ Technical Program Plan}

An intramural NIST research and standards development program applying High Performance Computing and

Communications technology to manufacturing applications.

James E. Fowler

U.S. DEPARTMENT OF COMMERCE

Technology Administration

National Institute of Standards

and Technology

Manufacturing Engineering Laboratory

Manufacturing Systems Integration Division

Gaithersburg, MD 20899-0001

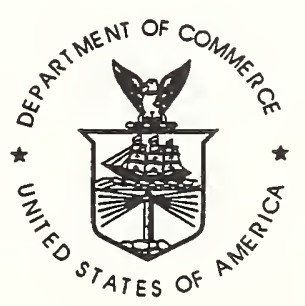

U.S. DEPARTMENT OF COMMERCE

William M. Daley, Secretary

TECHNOLOGY ADMINISTRATION

Mary L. Good, Under Secretary for Technology

NATIONAL INSTITUTE OF STANDARDS

AND TECHNOLOGY

Arati Prabhakar, Director 


\section{Program Office Staff}

The SIMA Program Office is responsible for managing and compiling information for all projects supported by the SIMA program. The SIMA Program Office staff are:

- James Fowler (Program Manager) jefowler@nist.gov

- Robert Densock (Computer Scientist)densock@cme.nist.gov

- Clarence Johnson (Program Analyst) ceejay@cme.nist.gov

- Brenda Thomasson (Secretary) blthomas@cme.nist.gov

\section{Disclaimer}

No approval or endorsement of any commercial product by the National Institute of Standards and Technology is intended or implied. Certain commercial equipment, instruments, or materials are identified in this report in order to facilitate understanding. Such identification does not imply recommendation or endorsement by the National Institute of Standards and Technology, nor does it imply that the materials or equipment identified are necessarily the best available for the purpose.

This publication was prepared by United States Government employees as part of their official duties and is, therefore, a work of the U.S. Government and not subject to copyright. 


\section{Table of Contents}

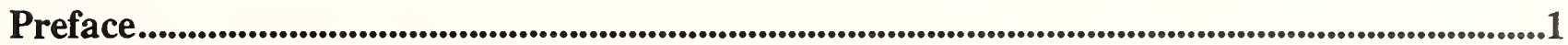

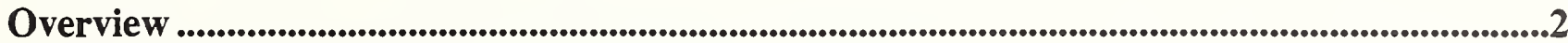

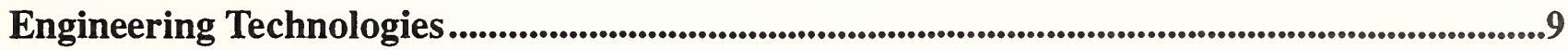

Manufacturing Technologies.................................................................................................................10

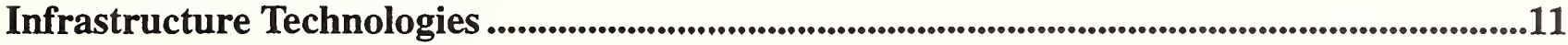

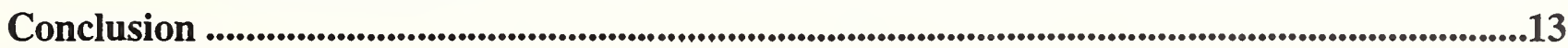

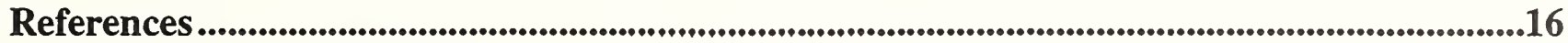

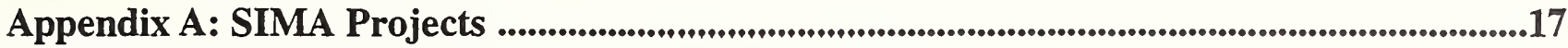

Manufacturing Systems Environment (MSE) Projects .........................................................17

[MSE1] Electronic Commerce of Component Information (ECCI) ….........................................................17

[MSE2] Information Protocols for Design ...................................................................................................17

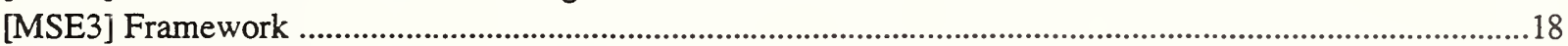

[MSE4] Manufacturing Enterprise Integration ......................................................................................18

[MSE5] Operator Interfaces for Virtual and Distributed Manufacturing ............................................................18

[MSE6] Process Planning Applications .......................................................................................................19

[MSE7] Process Plant Engineering and Construction ...................................................................................19

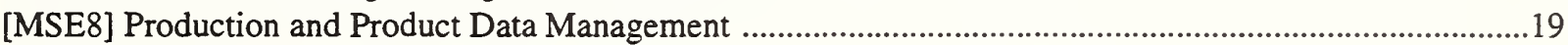

[MSE9] Rapid Response Manufacturing .....................................................................................................2

[MSE10] Reference Model Architecture …………………………........................................................2

[MSE11] STEP Application Protocols for Polymers Test Data .....................................................................2

[MSE12] STEP for the Process Plant Industry ................................................................................................2

[MSE13] Supply Chain Integration …………………………………………………………………….....

[MSE14] Unified Process Specification Language ……………….................................................................. 21

[MSE15] Virtual Environments and Visualization for Manufacturing ........................................................21

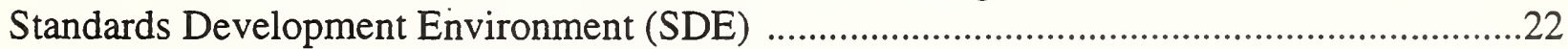

[SDE1] Application Protocol Development Environment …………………………………………….......22

[SDE2] Protocol Testing for Process Plant Representations ……………………………………………......2

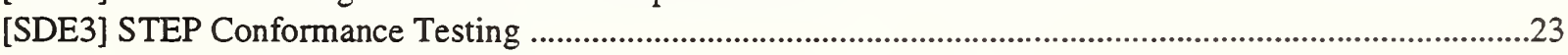

[SDE4] STEP Implementation Prototypes ....................................................................................................23

Testbeds and Technology Transfer Environment (TTTE) ....................................................23

[TTTE1] Advanced Manufacturing Systems and Networking Testbed (AMSANT) ........................................24

[TTTE2] Analysis Tools for Assessment and Optimization of Product and Process Design .............................24

[TTTE3] Green's Function Library for Advanced Materials Applications with Internet Access ......................24

[TTTE4] Integration of NIST Standard Reference Data into Information Networks ......................................2.25

[TTTE5] NIST Informatics Web Site Supporting Advanced Ceramics Applications .........................................25

[TTTE6] NIST Manufacturing Collaboratory ...........................................................................................26

[TTTE7] Online Access to NIST Chemical Reference Data .......................................................................26

[TTTE8] Standards for Exchange of Instrument Data and NIST Chemical Reference Data ............................26

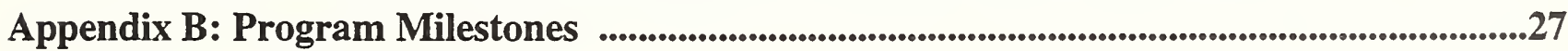




\section{Preface}

The Systems Integration for Manufacturing Applications (SIMA) Program is a major intramural effort being undertaken at the National Institute of Standards and Technology (NIST) to support the application of information technologies to the manufacturing domain. Initiated in 1994, the Program works with industry to develop technology solutions enabling integration of the systems used in the engineering and manufacturing of various kinds of products. The goals and supporting plans for the Program were originally described in [1]. The purpose of this report is to update the vision for the Program's technical activities and to identify project activities within the Program for FY97 and beyond.

The intended audience for this document includes private sector organizations and federal agencies collaborating with NIST, other agencies supporting the government initiative on High Performance Computing and Communications (HPCC), and the general public. This report is available via the SIMA Web page (http://www.nist.gov/sima/) or by electronic mail request to the SIMA Program Office secretary (blthomas@cme.nist.gov).

\section{Background}

The goal of the U.S. government's High Performance Computing and Communication (HPCC) Program is to accelerate the development of future generations of high performance computers and networks and the use of these resources in the government and throughout the U.S. economy. The HPCC Program was formally established by the High Performance Computing Act of 1991 (Public Law 102-194). The four original components ${ }^{1}$ of the HPCC Program were augmented in FY94 with a new component known as Information Infrastructure Technology and Applications (IITA) [2]. The IITA component supports research and development efforts that will enable integration of critical information systems and demonstrate feasible solutions to problems of national importance [3]. Twentyfirst century manufacturing, i.e., advanced manufacturing processes and products, is one of the challenges to be addressed by IITA activities [4]. Starting in FY97, the components of the HPCC Program are to be broadened and refocused into Program Component Areas (PCAs) [5]. These PCAs build on the foundations established in the previously identified component domains and continue to address the HPCC challenge problems. The PCAs are known as High End Computing and Computation, Large-Scale Networking, High Confidence Systems, HumanCentered Systems, and Human Resources, Education, and Training. The Human Centered Systems (HuCS) PCA which evolved from the IITA component - performs research and development making the products of computing systems and communication networks more easily accessible and useable to a wide range of user communities. Information interface issues are central to such research and development efforts.

NIST's SIMA Program is the agency's coordinating focus for its HPCC activities addressing the information interface needs of the U.S. manufacturing community. Specifically, the SIMA Program works with U.S. industry to:

- develop information exchange and interface protocol standard solutions to manufacturing integration problems,

- establish test mechanisms for validating solutions and implementations, and

- transfer information technology solutions to manufacturing enterprises.

These efforts will allow manufacturing industries to make use of the National Information Infrastructure (NII) as a mechanism for communicating product and process data among various manufacturing activities such as product/ process design, analysis, planning, scheduling, production, and quality control. Manufacturing applications require standard protocols for data exchange (information interfaces) to communicate with each other via NII technologies. The development of information interfaces between the communications infrastructure and manufacturing applications, between different manufacturing applications, and between these applications and their users will improve integration and thereby usability of these systems.

1. High Performance Computing Systems, National Research and Education Network, Advanced Software Technology and Algorithms, and Basic Research and Human Resources. 
Overview

\section{Overview}

The manufacture of a product requires materials, processing equipment, and skilled workers. This basic formula holds true regardless of whether the finished product is an electrical component, a mechanical component, a composite material, an electromechanical assembly, a transportation vehicle, a pharmaceutical product, or a factory itself. When considering the types of processing equipment used in contemporary manufacturing, many images spring to mind: furnaces, mixing vessels, transfer lines, machine tools, robots and so on. One type of manufacturing equipment which may not readily spring to mind is the computer. Computers are ubiquitous in manufacturing; they manifest themselves as embedded equipment controllers, production monitoring devices, and process control systems. The controllers, monitoring systems, and decision making systems used in manufacturing are networked together. These computers are as vital to the execution of the manufacturing process as they are to the operation of a modern automobile engine.

The notion of product or process engineering is often separated from that of product manufacturing despite the interdependencies between engineering and manufacturing. In comparison to manufacturing, the computer in engineering plays a much more obvious role. For carrying out engineering activities the computer is the principal piece of processing equipment employed. Supercomputers, high performance workstations, and personal computers are the tools of the trade for engineering practitioners. Engineers' computing systems are networked together with each other, with corporate information systems, and (sometimes) with those of the manufacturing operation's.

Taken together, product engineering and manufacturing are commonly referred to as the product realization process, i.e., all activities from product concept through delivery. Figure 1 illustrates some of the information necessary to carry out the product realization process. The figure is a portion of a graphical model describing activities in discrete mechanical product manufacturing [6]. The "Realize Products" box denotes an activity which requires information inputs such as production requirements, product orders, and materials knowledge. Physical inputs to the activity, e.g., tooling/materials, are shown in bold type in the figure. The "Realize Products" activity yields physical products as well as information such as cost estimates and equipment orders.

\section{The Manufacturing Software Integration Problem}

Just as a manufacturing process comes to a halt if the input materials which are being transformed into finished products are not available or are inappropriate, the computers used in the product realization process do not perform the jobs intended if needed information is unavailable or is incorrect when provided. The amount of information required for the product realization process is voluminous and thus the opportunities for information to be missing, incomplete, erroneous, or incompatible are enormous. Although the specific types of information will vary according to manufacturing sector, processes used, and product type, the volume of information is comparable for most industries. Consider the decomposition of the "Realize Products" activity into the five activities shown in Figure 2. The information which is conveyed between and shared among these five lower level manufacturing activities is illustrated. Each of those activities could again be decomposed into multiple sub-activities and those sub-activities could be decomposed until eventually the multitude of information necessary to enact the realization of a product would be revealed.

The information conveyed between product realization activities may exist on paper or it may exist in digital form. It's safe to say that if the information exists on paper today there is high likelihood that it will be available in a digital form in the very near future. Suppose that all of the information needed to support product realization were available in a digital form. If that were the case wouldn't the systems used by design engineers, manufacturing engineers, process engineers, machine operators, and administrators exchange all of that information with each other over a company's internal network? Wouldn't manufacturers be able to exchange information at will with their customers and suppliers through an external network? Unfortunately the answer to both questions is no - as anyone who has used computers in these activities will attest. The reason why such information exchanges would not be successful has little to do with network connectivity or with the types of computers used or with the operating systems on those computers. The information exchange problems would largely be attributed to the software applications that the 


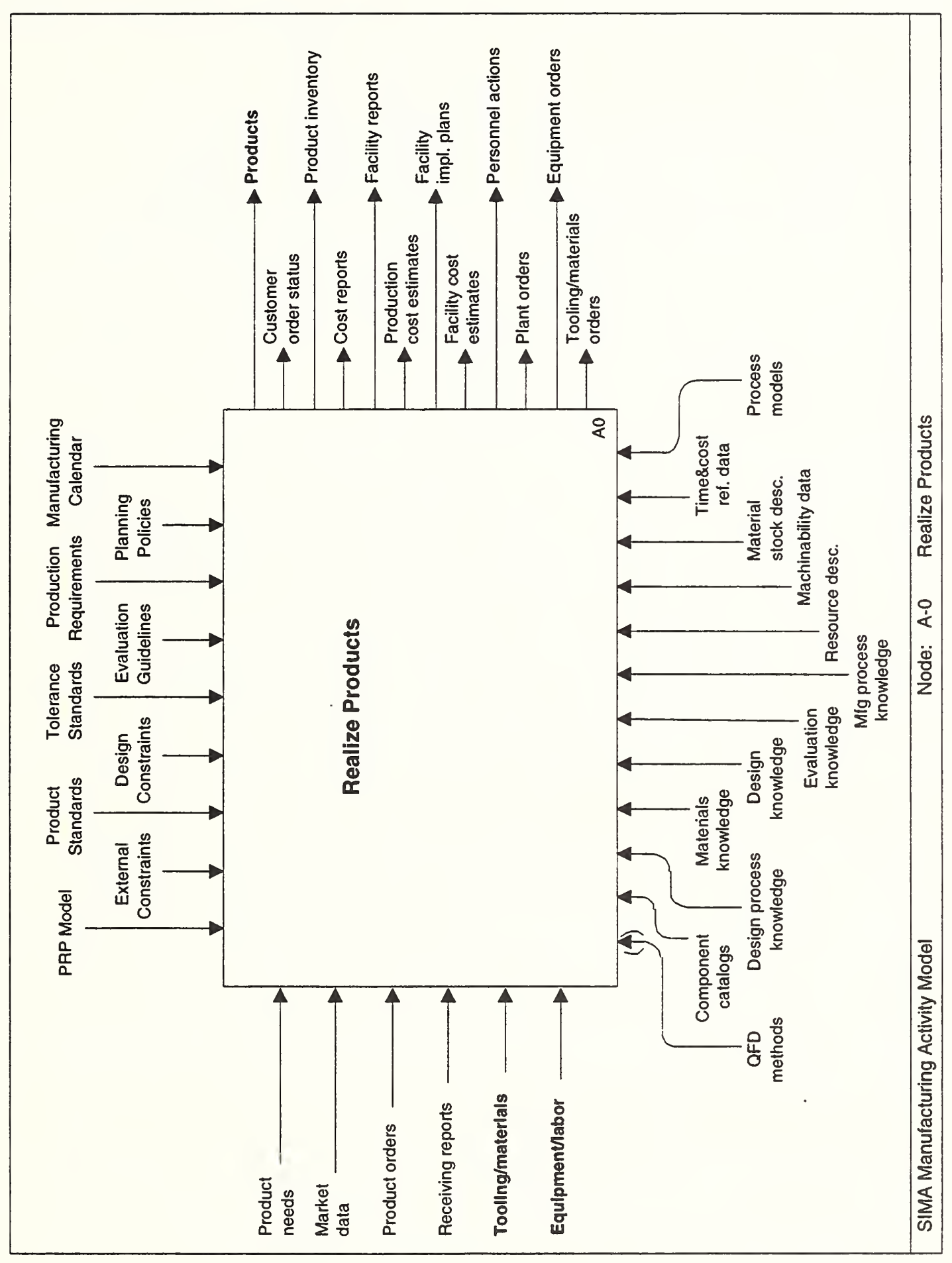

䓪 


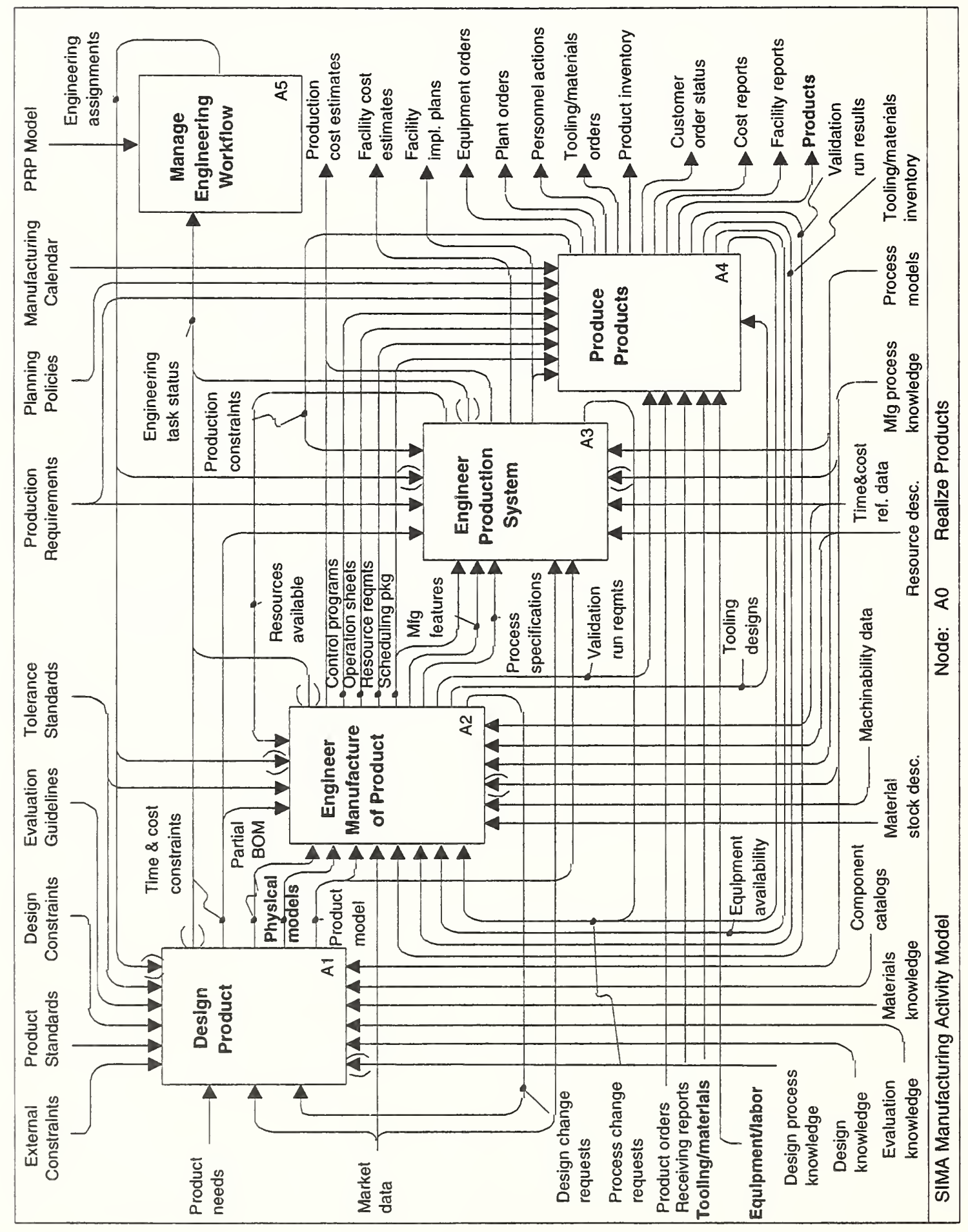

 
designers, manufacturing engineers, process designers, machine operators, and administrators use to do their jobs. Simply put, they lack commonly defined interfaces through which the software applications can exchange information with each other. Without information interfaces between the software applications, there is no exchange of information and hence, no effective communication. Without effective communication among engineering systems, manufacturing systems, supplier's systems, and customer's systems, the product realization process is slower, more costly, and reduces competitiveness.

\section{Intranet and Extranet Communication Solutions}

The widespread deployment of internet browsing software such as Microsoft Corporation's Internet Explorer, the National Center for Supercomputing Applications' Mosaic, and Netscape Communication Corporation's Navigator enable companies to make information easily accessible across local and wide area networks. Such browsing software in conjunction with information servers and an underlying network infrastructure allows a business enterprise to disseminate and share all manner of business information efficiently, rapidly, and with a uniform user interface. As implemented within a single enterprise -- regardless of whether the enterprise is one facility or multiple, geographically separated facilities -- this combination of information and information dissemination mechanisms is known as an intranet. When an enterprise exposes some or all of its internal intranet to its external partners through appropriate use of network security mechanisms, the intranet becomes an extranet. Through an extranet an enterprise can selectively share information with its partners (be they suppliers, collaborators, or customers) and vice versa.

It is presumptuous to conclude that intranets or extranets provide a solution to the manufacturing software integration problem. The key is to recognize that the information shared through these mechanisms is meant for human consumption. Consider a situation where a manufacturing enterprise has a partnership with a parts supplier. The parts supplier provides the manufacturer with access to the supplier's most up-to-date part specifications, availability, and manufacturer-specific ordering information via an on-line catalog which is accessed using an internet browser. This enables any of the manufacturer's design engineers to search the supplier's catalog of parts from their desktop workstations and view detailed design specifications for the supplier's parts. The engineers would conceivably want to download information about selected parts directly onto their desktop workstations so that the component part designs could be evaluated in conjunction with the product assemblies the designers are developing. But would they be able to directly download a geometric model of the supplier's part and incorporate it directly into their design systems to determine whether a part fits into an assembly? The intranet/extranet solution does not address this question. The answer depends on compatibility between the design software that the component supplier and the manufacturer's design engineers use.

The success and ubiquitousness of internet browsers stems from compatibility among the browsers, the information servers, and the network infrastructure. This compatibility is due to open standards such as Transmission Control Protocol (TCP) [7] and Internet Protocol (IP) [8], along with specifications which are well on their way to becoming formal standards (i.e., Hypertext Markup Language (HTML) [9], Hypertext Transfer Protocol (HTTP) [10], and Uniform Resource Locators [11]). Were it not for these open standards, browsers from different vendors would neither readily interoperate with servers from different vendors, nor would they interoperate with the available network hardware and software infrastructure. Just as those non-proprietary standard specifications are fundamental to compatibility among information content providers, network providers, and users, it is clear that open standards will be fundamental to compatibility among the myriad of systems used throughout the product realization process.

\section{Standards-based Integration Solutions}

Voluntary standards come into existence through several mechanisms [12]. A formal standard arises through agreement by a committee of technical representatives formed under the auspices of a formal standards-making body, e.g., the International Organization for Standardization (ISO) and the American National Standards Institute (ANSI). Informal or de facto standards are those that have not been submitted to a formal-standards making body but are nonetheless adhered to in multiple independent implementations. Such standards are more common in the software domain than in other areas. De facto standards arise through dominance in the market of a particular mechanism, resulting in the de facto standardization of its characteristics. Another variant of an informal standard is one arising 
through (tacit) agreement among a group of vendors to adhere to a common interface so that their products interoperate, thus creating a "standard" within their combined customer base - this is sometimes referred to as an "industry standard."

Many informal standards eventually become formal standards through ratification by a standards-making body. The advantage of creating a standard first through informal means and following with formal ratification is that in virtually all such cases implementations of the specification have evolved with the maturation of the specification. The side-effect of this parallel evolution of the specification and implementations is that the specification has been refined to reflect implementation and usability concerns. For these reasons the SIMA Program has adopted a process for development of manufacturing software integration specifications taking into account the advantages of both the informal and formal standard development tracks. Specifications developed through this process will be known as "Initial Manufacturing Exchange Specifications" (IMESs). Notable aspects of the process to develop an IMES -- the IMES process -- are described below. For further details, the reader is referred to the report describing the IMES concept [13].

\section{The IMES Process}

Before delving into the methodology to be used for development of an IMES, the characteristics of an IMES must first be discussed. In general it is the specification of an interface between software systems to be used in supporting a particular manufacturing activity or manufacturing scenario. As such it will be a proposed solution aimed at improving interoperability among independently developed manufacturing software systems. Three general classes of IMESs have been conceived:

- an interface specification between a human and a software application,

- an interface specification between two or more software applications, or

- a reference information repository specification.

The last IMES type refers to a specification for the contents of a repository (typically a database) which is used to provide information to many activities, the contents of which are updated by only a single process (typically an administration process).

An MES is developed through an industry review and consensus process and is accepted by the manufacturing community as a definitive solution to a particular interoperability problem. A complete IMES:

- specifies the scope and domain of its applicability along with a supporting manufacturing scenario,

- specifies the interface or information repository,

- identifies its status as of publication in formal standards organizations,

- states the implementations available, and

- references the source documents (related standards) from which it is derived or on which it depends. 
The development of an IMES involves seven phases. The execution of these phases needs not occur sequentially -some may overlap while others may occur in parallel. Figure 3 illustrates the seven phases showing how results from

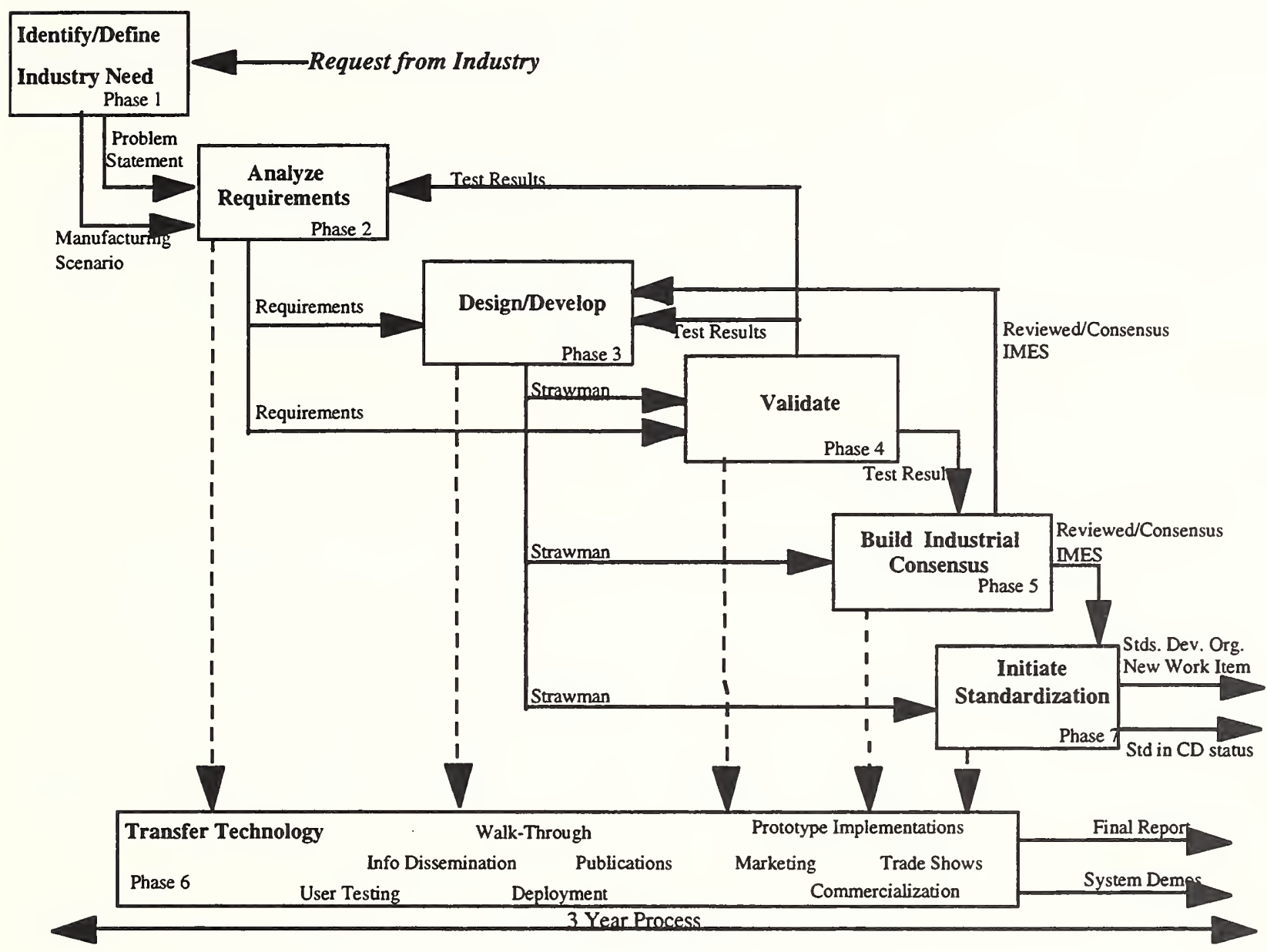

Figure 3. IMES Process Activities

each phase are used by the others. The individual phases are described as follows:

\section{Phase 1: Identify/Define Industry Need}

The initial activity of IMES development is identifying and documenting an industry need, manufacturing scenario, or problem statement to define the scope and manufacturing domain of the proposed project. This need could be identified in several ways. Industrial collaborators are to be involved in defining this need.

\section{Phase 2: Analyze Requirements}

This IMES development phase consists of analyzing the current situation within the manufacturing scenario to understand current capabilities, prior attempts at a solution, and specific needs that must be accommodated in the proposed IMES solution. A requirements specification is the primary desired output from this project phase. Such a specification will enable widespread industry review of the detailed requirements which a solution must satisfy in a form that is understandable by the majority of the target manufacturing community. 


\section{Phase 3: Design/Develop}

This IMES development phase consists of the actual design, development, and documentation of the proposed IMES technical solution which satisfies the requirements specified in the previous phase. The solution may consist of a combination of deliverable types, including information model(s), interface protocol(s), or process model(s), as required by the problem to be solved. The primary output of this phase is the initial version of the strawman proposal for external review.

\section{Phase 4: Validate}

A validation phase is required to ensure the completeness, validity, and usability of the proposed IMES solution. Validation activities may take several forms, including prototype implementations, detailed walk-through with domain experts, or a comparison with known references. A proposed solution with demonstrated prototype implementations and validation test results makes a much stronger case for standardization. The documented test results (based upon the prototype implementation, test environment, test suites, or other validation tools) are considered the primary output of this phase.

\section{Phase 5: Build Consensus}

By definition, an IMES is developed from an industry consensus viewpoint. Whereas most IMES development phases require some collaboration or interaction with industrial counterparts, this phase of IMES development requires interaction with a large segment of the target manufacturing community. This interaction can be accomplished through technical workshops, user group meetings, correspondence, or site visits. IMES development projects should endeavor to obtain and accommodate as much input and feedback from industry as possible in the proposed project solution. True consensus may never be reached. This project phase is deemed necessary, however, for positioning and delivering a quality-proposed strawman for standardization to an appropriate standards development organization. This phase is differentiated from the actual standardization process to allow and encourage other consensus-building activities without the potential constraints and procedures required by standards organizations. The primary deliverable of this phase is an updated Strawman IMES resulting from the consensus-building activities. In some cases, significant comments and suggestions may indicate the need for the project to iterate back to the IMES Design/ Develop Phase 3.

\section{Phase 6: Transfer Technology}

One of the primary missions of NIST is to disseminate results to industry. The SIMA Program supports this mission. IMES development efforts will include aspects of technology transfer to publicize, market, and transition project activities and results to industry or standards development organizations. Technology transfer should be an ongoing project activity. Various methods of technology transfer can be employed at the various stages of the IMES development effort to supply industry collaborators and the manufacturing community with current information. The primary deliverables for this phase consist of a final report and system demonstrations.

\section{Phase 7: Initiate Standardization}

Since an IMES is a proposed standard solution to a manufacturing integration need, IMES development efforts must include interaction with appropriate standards development organizations to initiate this standardization. These activities may include attending standards meetings, participating on various standards committees, or writing project correspondence with standards development organization conveners. The objective of this phase is to initiate the proposed standards work (either as a new work item or modifications to existing standards/work items) to a point where it will be self-sustaining within the standards development organization.

\section{Program Vision}

By combining a standards-based approach with an appropriately scaled network infrastructure we envision a product realization environment comprised of an unlimited variety of software components which communicate without loss of information and without waste of time. This is not to say that instantaneous computer communication will be the norm in a world of ever-increasing network bandwidth (and commensurately increasing network traffic). Rather the focus of this vision is eliminating the loss of productivity attributed to re-entering information due to incompatible manufacturing software interfaces and the time lost correcting faulty or incomplete information exchanges. The 
opportunities for such time losses multiply with the availability of every new software system in the marketplace. The types and numbers of software packages available for use in various aspects of the product realization process have grown over the last decade and there is no reason to believe that this trend will halt. Keeping that vision in mind, the SIMA Program must work not only to develop specific integration solutions between classes of manufacturing applications and among applications within the same class, but also generic integration solutions which will be applicable to many classes of manufacturing applications.

The SIMA Program encompasses 27 projects throughout all of NIST's Laboratories ${ }^{1}$. Approximately half of the projects are actively developing IMESs. The remainder of the projects are typically addressing manufacturing systems integration problems which are not appropriately addressed through interoperability specifications. A brief summary of all SIMA projects is found in Appendix A. For a summary of Program milestones planned, refer to Appendix B. Additional information about project activities in previous years can be found in [14]. In the following sections we look at the Program's planned development efforts according to the product realization process areas that will benefit from the Program's results: Engineering, Manufacturing, and Infrastructure.

\section{Engineering Technologies}

When engineers are tasked with designing a solution to a problem there are multiple methodologies which may be followed while synthesizing a solution. Frequently an existing, related solution is examined to see if or how that solution may be adapted to the problem at hand. Re-using existing designs requires the ability to search a repository of past solutions and a means to identify the appropriateness of the existing designs to the current problem. In order to make this process more efficient than a manual search, representations of design characteristics are necessary which support re-use. The Information Protocols for Design [MSE2] ${ }^{2}$ project is working on a series of IMESs which will enable characterization of mechanical design characteristics such as functionality, behavior, and structure through representations for constraints, design knowledge, rationale, design features, and parametric information. In the electrical product domain, the Electronic Commerce of Component Information (ECCI) [MSE1] project is developing an IMES for a printed circuit repository which will enable designers to search for and identify electrical components appropriate for inclusion in an overall product design. The IMESs under development in these two projects will ultimately enable more efficient access to existing design information and better usability of such information by design engineers. For chemical products the Online Access to NIST Chemical Reference Data [TTTE7] project is developing an internet site enabling interactive search of NIST's standard reference chemical data by substance name or chemical structure specification allowing designers to obtain property characteristics necessary for chemical design.

Regardless of whether a design solution is to be adapted from an existing solution or developed anew, multiple analyses are performed to ensure that the proposed solution is viable. Such analyses take many different forms depending on the product domain, product function, and manufacturing processes to be employed. In addition to the IMESs mentioned above the Information Protocols for Design [MSE2] project is also working on an IMES addressing information exchange issues between design software and finite element analysis software for mechanical products. Analysis of product designs employing anisotropic materials is computationally expensive and timeconsuming; with the Green's Function Library for Advanced Materials Applications with Internet Access [TTTE3] project engineers will have access to an internet library of pre-computed material behavior results which will improve the usability and availability of such analyses. For engineers performing statistical analyses of process designs or product variation the Analysis Tools for Assessment and Optimization of Product and Process Design [TTTE2]

1. Building and Fire Research; Chemical Sciences and Technology; Electrical and Electronics Engineering; Information Technology; Manufacturing Engineering; Material Science and Engineering; and Physics.

2. In this and the following two sections project names are notated with the designation found in the project summaries given in Appendix A. 
project is developing an internet site enabling interactive guidance for selection of statistical methodologies, access to statistical tools, and guidelines for interpretation of analysis results. For analyses comparing performance characteristics of materials information the NIST Informatics Web Site Supporting Advanced Ceramics Applications [TTTE5] is working towards development of an internet site providing access to international databases of materials characteristics. For scientists using laboratory instrumentation to perform chemical analyses, the Standards for Exchange of Instrument Data and NIST Chemical Reference Data [TTTE8] project is developing an IMES which will provide a common data interface between instrumentation hardware and analytical software. Addressing interoperability issues with respect to materials analysis, the STEP Application Protocols for Polymers Test Data [MSE11] is developing an IMES characterizing test data necessary for assessment and selection of polymer formulations for plastic components. Engineers developing devices whose operation include electromagnetic measurement will want to compare target performance with reference data sets being made available on an internet site under development in the Integration of NIST Standard Reference Data into Information Networks [TTTE4] project.

Production considerations are another factor in the development of an appropriate design solution. Early exchange of information between engineering design staff and manufacturing engineering staff helps ensure that manufacturing costs are understood in advance of actual production, that production time will be within expectations, and that selected manufacturing processes are appropriate to quality goals. The Electronic Commerce of Component Information (ECCI) [MSE1] project is working to develop a formal standard characterizing the information needed to convey printed circuit assembly information between designers and manufacturers. When designing an assembly of mechanical components, it is beneficial to know during the design stage how manufacturing assembly processes can be performed. The Information Protocols for Design [MSE2] project is developing an IMES characterizing the exchange of information between virtual assembly systems and design systems. Changes to the configuration of an existing production system are frequently necessary to support the manufacture of a new product. The Production and Product Data Management [MSE8] project is developing an IMES characterizing the information needed to describe factory layout specifications. To support the design of chemical manufacturing plants, the STEP for the Process Plant Industry [MSE12] project is participating in the development of a formal standard specifying the information necessary to characterize process plant configurations, while the Protocol Testing for Process Plant Representations [SDE2] is working on validating industrial implementations of those specifications.

Industrial enterprises intending to introduce draft IMESs or even new, formal standards into their product realization process will do so in a controlled fashion so as not to create undesirable side-effects in their business activities should problems arise. The Automotive Industry Action Group has established a project working towards the introduction of the international standard for configuration controlled 3-dimensional design information [15] among the U.S. automakers and their suppliers. The STEP Implementation Prototypes [SDE4] project facilitates this industrial effort with the testing of the standard in particular exchanges between the suppliers and the automakers to better understand the inter-relationships between the implementation of the standard and the engineering practices in which the standard is intended to work.

\section{Manufacturing Technologies}

Selecting manufacturing processes, sequencing manufacturing operations, and scheduling manufacturing processes are all activities central to the execution of the production process. In order to make informed decisions when selecting processing equipment manufacturing engineers need to know the capabilities of the equipment under consideration. The Rapid Response Manufacturing [MSE9] project is addressing this issue by developing an IMES characterizing the descriptions of machine tools and cutting tools so that their descriptions are available to multiple systems from a common database. In the mechanical product manufacturing domain, process engineers select metal removal operations with the aid of process planning software systems. The Process Planning Applications [MSE6] 
project is participating in the validation of a formal international standard which characterizes the information to be exchanged between those systems and the software systems used to control machine tools. That project is also in the initial stages of defining an IMES to improve interoperability between design systems and process planning systems.

Appropriately scheduling equipment operations on the shop floor is fundamental to achieving desired production rates and minimizing down-time. Dynamic scheduling requires knowledge of the current state of the shop floor so that information can be used to reschedule as needs arise. The Production and Product Data Management [MSE8] project is developing an IMES characterizing the information needed to interface shop floor data collection systems with scheduling systems. That project is also looking to develop better interfaces between the process planning activity and the scheduling function. In order to test the specifications under development in that project, a virtual production facility has been developed whereby the operation of an entire production facility is simulated. The virtual production facility has evolved from simulations of single machine tools to simulations of work cells, material handling systems, assembly areas, and human operators. A linked project, Virtual Environments and Visualization for Manufacturing [MSE15], is investigating the representations necessary for kinematics and ergonomics virtual environments, particularly those which are remotely accessed via internet browsing software. As SIMA's virtual production capabilities continue to be enhanced they will serve as test platforms for many of the IMESs being developed throughout the Program.

While the virtual production facility will provide the SIMA Program with capabilities for simulated testing of several types of IMESs, another active area of development is the specification and testing of remote interfaces to physical production facilities. Such interfaces allow engineers at one physical location to monitor and control equipment at a different location. The Operator Interfaces for Virtual and Distributed Manufacturing [MSE5] project is investigating the issues of what information is necessary to enable such interactions and what kinds of virtual environments best allow engineers to easily acquire operational information and submit control inputs. The project will be testing the specifications developed through implementation of remote interfaces to NIST's Hexapod milling machine.

Local control of equipment on the manufacturing shop floor is performed by a combination of software, general purpose computers, and specialized control systems. The typical manufacturing facility includes manufacturing equipment from a variety of vendors with many types of equipment having their own specialized interfaces. Yet in order to take advantage of data collection software, dynamic scheduling, and intelligent control of manufacturing processes there need to be in place standardized interfaces to the manufacturing equipment's software systems. This is the area of development that the Reference Model Architecture [MSE10] project is addressing through specification of software interfaces and a manufacturing control system architecture. This project will also be testing the specifications developed through implementation on NIST's Hexapod and on NIST's coordinate measuring machines.

\section{Infrastructure Technologies}

It's clear that numerous information interface issues arise in the software systems used to carry out the product realization process. Even if IMESs, de facto standards, and formal standards all existed today which were necessary to address all individual interface problems the question of how those specifications relate to each other would remain. Is there a mechanism by which an industrial enterprise could configure their software systems and the interfaces among these software systems coherently? It is precisely these kinds of questions that the Framework [MSE3] project is investigating. Through analysis of a representative set of specifications and testing in a distributed object communication environment the project is working to ensure that interface solutions can work together for the industrial enterprise as a whole. A closely linked project, the Manufacturing Enterprise Integration [MSE4] project is actively working in the formal standards arena to develop the models necessary to characterize how integration specifications can be related to each other. 
Affecting all aspects of the product realization process is the management of the numerous data files which come into existence along with the design and manufacture of a product. In the mechanical product domain, these data files can include product requirement specifications, design files, drawing files, processing operation specifications, equipment control programs - each existing in multiple revisions and versions corresponding to the history and usage of the product. Commercial Product Data Management (PDM) software systems seek to instill order in what may easily become a confusing set of relationships among software systems, data, and product configurations. As the need for PDM systems and the benefits they provide has increased so has recognition of the need for an interface to these systems which are so obviously linked to engineering and manufacturing software applications. The Production and Product Data Management [MSE8] project is developing an IMES characterizing such an interface to PDM systems in conjunction with numerous other organizations who have also recognized this vital need. This interface will enable the applications which engineers use to directly access PDM systems and thereby make their capabilities more easily accessible to the engineering users.

Many PDM systems also incorporate functionality for managing workflow, e.g., ensuring that data files progressing through the product realization process get to the people they are supposed to and tracking that progress throughout the process. The representation of the workflow process itself is an active area of interest, particularly to companies interested in linking together over a network to form temporary virtual enterprises for particular endeavors of common interest. The Unified Process Specification Language [MSE14] project is developing an IMES characterizing the generic representation of processes. Since the representation is intentionally generic, it will be useful for representation of engineering processes, manufacturing processes, administrative processes and so on. Having such representations for processes will enable software systems to be configured with more accurate models of real-life behavior and will also further enable these representations to be shared and understood among different organizations - be they within the same company or among different companies.

Networks, common information formats, and software applications provide the basic tools enabling people from different organizations to work together regardless of geographic location. But in order for remote collaborators to interact with each other in a manner similar to that if they were geographically co-located there needs to be further development and enhancement of the existing collaboration environment. The NIST Manufacturing Collaboratory [TTTE6] project is exploring the software tools and techniques available for such collaborative interactions. This project will be field-testing these mechanisms both within NIST for SIMA project participants as well as between the projects' participants and their external collaborators. One of the first candidates for use of a collaboratory environment is the Application Protocol Development Environment [SDE1] (APDE). The APDE project is working with the ISO subcommittee responsible for product data standards to accelerate the development of those specifications by applying information technology to the standards development process. Since that process by its very nature requires collaboration among technical experts throughout the world it is ideally suited to benefit from collaboratory technologies.

Regardless of how information interface specifications are developed, their value is determined by their acceptance in the marketplace. While it may be argued that a variety of technical and non-technical conditions may factor into the marketplace's decision to embrace a specification, everyone will agree that the question of whether or not the specification works is fundamental to its acceptance. Specification testing is the only way to answer that crucial question. Prototype implementations of a specification are typically used to prove feasibility of the solution that the specification proposes while at the same time gaining experience in its implementation. But once a specification has been finalized and commercial implementations become available, the quality of the specification is no longer judged conceptually but rather by how well vendors' implementations satisfy its requirements. The STEP Conformance Testing [SDE3] project is working to develop software testing capabilities which can automatically assess how well vendors' implementations of specifications meet their intended functions. This testing service allows vendors to privately test their implementations and refine them based on a set of metrics common to all such implementations. This service benefits both the vendors, by enabling early detection of implementation problems, and the users of the vendors' software, by ensuring that the expected interoperability among different systems is actually supported. The project is focussing on developing an extensible testing environment so that it can be readily adapted to provide 
testing capabilities for numerous specification contexts. One early beneficiary of the project's testing capabilities has been the STEP Implementation Prototypes [SDE4] project's support for the Automotive Industry Action Group effort to test how well one product data standard works for design data exchanges between automakers and their suppliers.

\section{Conclusion}

The product realization process is rife with information-intensive activities. The premise of the SIMA Program is that the systems which people use to create and transform information throughout the product realization process do not allow for exchange of information as well as is required. There is ample evidence to support the assertion that manufacturers in all industrial domains face an ever-increasing number of information interface problems. This phenomena is due to the plethora of different types of software systems already existing in manufacturing enterprises, acquisitions of new and previously unknown types of software systems, and the need to meaningfully exchange information between all of these systems within an enterprise as well as among those software systems found throughout the entire supply chain.

The SIMA Program's projects work with their industrial partners to identify information needs among product realization activities, between what software systems, in what contexts, and to define the mechanisms appropriate to perform those exchanges. Addressing these interface problems makes the managers, scientists, engineers, and manufacturing personnel using those systems more productive and increases the return on an enterprise's computing and software investments. Table 1 below summarizes the anticipated progress of SIMA projects toward development of specifications intending to resolve specific information interface problems through the Program's IMES process. As these solutions progress toward broad industrial consensus, they will be formalized through appropriate standards organizations. Several SIMA projects' technical solutions have reached that level of formal international acceptance, as evidenced by their status in the formal standards process shown in Table 2. By maintaining a neutral perspective in the testing of information interfaces for engineering and manufacturing the Program ensures that validated solutions addressing the common requirements of both users and software providers can be adopted.

\begin{tabular}{|l|l|l|l|}
\hline \multirow{4}{*}{ Project Name } & IMES Name & $\begin{array}{l}\text { Expected } \\
\text { FY97 } \\
\text { Phase(s) }\end{array}$ & $\begin{array}{l}\text { Expected } \\
\text { FY98 } \\
\text { Phase(s) }\end{array}$ \\
\hline \hline \multirow{4}{*}{$\begin{array}{l}\text { Electronic Commerce of Com- } \\
\text { ponent Information (ECCI) }\end{array}$} & Object Oriented Printed Circuit Repository Specification & 2 & 3,4 \\
\cline { 2 - 4 } & Data Dictionary Specification & 3,4 & 4,5 \\
\cline { 2 - 4 } & Best Practices Methodology & 2 & 3 \\
\cline { 2 - 4 } & Product Information Viewer Specification & 3,4 & $5,6,7$ \\
\hline \multirow{4}{*}{$\begin{array}{l}\text { Information Protocols for } \\
\text { Design }\end{array}$} & Knowledge-based Design - CAD Integration & 1 & 2 \\
\cline { 2 - 4 } & Virtual Reality-based Design - CAD Integration & 2 & 3 \\
\cline { 2 - 4 } & Solid Interchange Format & 1,2 & 3 \\
\hline Framework & $\begin{array}{l}\text { CIM Framework: Manufacturing Object Class Generali- } \\
\text { zation }\end{array}$ & 4 & 5,6 \\
\cline { 2 - 4 } & $\begin{array}{l}\text { Object Request Broker Interface for Real-time Applica- } \\
\text { tions }\end{array}$ & 1,2 & 3,4 \\
\cline { 2 - 4 } & $\begin{array}{l}\text { Framework Representation of Manufacturing Systems } \\
\text { Integration Specifications }\end{array}$ & 6 & \\
\cline { 2 - 4 } & Dimension Inspection & 2,3 & 4,5 \\
\hline
\end{tabular}

TABLE 1. IMES's By Project 


\begin{tabular}{|c|c|c|c|}
\hline Project Name & IMES Name & $\begin{array}{l}\text { Expected } \\
\text { FY97 } \\
\text { Phase(s) }\end{array}$ & $\begin{array}{l}\text { Expected } \\
\text { FY98 } \\
\text { Phase(s) }\end{array}$ \\
\hline $\begin{array}{l}\text { Operator Interfaces for Virtual } \\
\text { and Distributed Manufacturing }\end{array}$ & Operator Display Conversion Specifications & $1,2,3$ & $\overline{3,4}$ \\
\hline Process Planning Applications & Design - Process Planning Interface Specification & $1,2,3$ & 4 \\
\hline \multirow[t]{4}{*}{$\begin{array}{l}\text { Production and Product Data } \\
\text { Management }\end{array}$} & $\begin{array}{l}\text { Scheduling - Shop Floor Data Collection Integration } \\
\text { Specification }\end{array}$ & 2,3 & 4,5 \\
\hline & Product Data Management Interface & 2,3 & 4,5 \\
\hline & Plant Layout - Simulation Integration Specification & 2,3 & 4,5 \\
\hline & Assembly - Simulation Integration Specification & 2 & 3,4 \\
\hline Rapid Response Manufacturing & Manufacturing Resource Data Representation & $4,5,6,7$ & 7 \\
\hline \multirow[t]{4}{*}{ Reference Model Architecture } & Generic Control Node Specifications & 3,4 & 4,5 \\
\hline & Plan Interface Specifications & 3,4 & 4,5 \\
\hline & Human Oversight Interface Specifications & 3,4 & 4,5 \\
\hline & Message Suite Specifications & 3,4 & 4,5 \\
\hline $\begin{array}{l}\text { STEP Application Protocols for } \\
\text { Polymers Test Data }\end{array}$ & Polymers Test Data Specifications & 1 & 1 \\
\hline $\begin{array}{l}\text { Unified Process Specification } \\
\text { Language }\end{array}$ & Process Specification Model & $1,2,3$ & 3,4 \\
\hline \multirow{2}{*}{$\begin{array}{l}\text { Standards for Exchange of } \\
\text { Instrument Data and NIST } \\
\text { Chemical Reference Data }\end{array}$} & Analysis Data Interchange Specifications & 3 & 4,5 \\
\hline & Standard Instrument Capability Dataset Specification & 3 & 4,5 \\
\hline
\end{tabular}

TABLE 1. IMES's By Project

\begin{tabular}{|l|l|l|l|}
\hline \multicolumn{1}{|c|}{ Project Name } & Standard Designation & $\begin{array}{l}\text { Expected } \\
\text { FY97 } \\
\text { Status }\end{array}$ & $\begin{array}{l}\text { Expected } \\
\text { FY98 } \\
\text { Status }\end{array}$ \\
\hline \hline $\begin{array}{l}\text { Electronic Commerce of Com- } \\
\text { ponent Information (ECCI) }\end{array}$ & $\begin{array}{l}\text { ISO 10303-210 Electronic Assembly, Interconnect, and } \\
\text { Packaging Design }\end{array}$ & $\begin{array}{l}\text { Commit- } \\
\text { tee Draft }\end{array}$ & $\begin{array}{l}\text { Draft Inter- } \\
\text { national } \\
\text { Standard }\end{array}$ \\
\hline \multirow{2}{*}{ Framework } & $\begin{array}{l}\text { ISO 10303- 26 Interface Definition Langauge Binding to } \\
\text { the Standard Data Access Interface Specification }\end{array}$ & $\begin{array}{l}\text { Commit- } \\
\text { tee Draft }\end{array}$ & $\begin{array}{l}\text { Draft Inter- } \\
\text { national } \\
\text { Standard }\end{array}$ \\
\hline Rapid Response Manufacturing & $\begin{array}{l}\text { ISO 13399-1 Computerized Machining Data Exchange: } \\
\text { Overview and Fundamental Principles }\end{array}$ & $\begin{array}{l}\text { Working } \\
\text { Draft }\end{array}$ & $\begin{array}{l}\text { Commit- } \\
\text { tee Draft }\end{array}$ \\
\cline { 2 - 5 } & $\begin{array}{l}\text { ISO 13399-2 Computerized Machining Data Exchange: } \\
\text { Reference Hierarchy }\end{array}$ & $\begin{array}{l}\text { Working } \\
\text { Draft }\end{array}$ & $\begin{array}{l}\text { Commit- } \\
\text { tee Draft }\end{array}$ \\
\cline { 2 - 4 } & $\begin{array}{l}\text { ISO 13399-3 Computerized Machining Data Exchange: } \\
\text { Turning Tools Data }\end{array}$ & $\begin{array}{l}\text { Working } \\
\text { Draft }\end{array}$ & $\begin{array}{l}\text { Commit- } \\
\text { tee Draft }\end{array}$ \\
\hline Process Planning Applications & $\begin{array}{l}\text { ISO 10303-213 Numerical Control Process Plans for } \\
\text { Machined Parts }\end{array}$ & $\begin{array}{l}\text { Final Draft } \\
\text { Interna- } \\
\text { tional Stan- } \\
\text { dard }\end{array}$ & $\begin{array}{l}\text { Interna- } \\
\text { tional Stan- } \\
\text { dard }\end{array}$ \\
\hline
\end{tabular}

TABLE 2. Standards by Project 


\begin{tabular}{|l|l|l|l|}
\hline \multicolumn{1}{|c|}{ Project Name } & Standard Designation & $\begin{array}{l}\text { Expected } \\
\text { FY97 } \\
\text { Status }\end{array}$ & $\begin{array}{l}\text { Expected } \\
\text { FY98 } \\
\text { Status }\end{array}$ \\
\hline \hline $\begin{array}{l}\text { Process Plant Engineering and } \\
\text { Construction }\end{array}$ & ISO 10303-230 Building Structural Frame: Steelwork & $\begin{array}{l}\text { Commit- } \\
\text { tee Draft }\end{array}$ & $\begin{array}{l}\text { Draft Inter- } \\
\text { national } \\
\text { Standard }\end{array}$ \\
\hline $\begin{array}{l}\text { STEP for the Process Plant } \\
\text { Industry }\end{array}$ & ISO 10303-227 Plant Spatial Configuration & $\begin{array}{l}\text { Draft Inter- } \\
\text { national } \\
\text { Standard }\end{array}$ & $\begin{array}{l}\text { Interna- } \\
\text { tional Stan- } \\
\text { dard }\end{array}$ \\
\cline { 2 - 4 } & $\begin{array}{l}\text { ISO 10303-231 Process Engineering Data: Process } \\
\text { Design and Process Specification }\end{array}$ & $\begin{array}{l}\text { Commit- } \\
\text { tee Draft }\end{array}$ & $\begin{array}{l}\text { Draft Inter- } \\
\text { national } \\
\text { Standard }\end{array}$ \\
\hline $\begin{array}{l}\text { Virtual Environments and Visu- } \\
\text { alization for Manufacturing }\end{array}$ & ISO 14772: Virtual Reality Modeling Language & $\begin{array}{l}\text { Commit- } \\
\text { tee Draft }\end{array}$ & $\begin{array}{l}\text { Draft Inter- } \\
\text { national } \\
\text { Standard }\end{array}$ \\
\hline
\end{tabular}

TABLE 2. Standards by Project

Naturally the Program cannot tackle every specific interface problem existing or foreseen. SIMA does foster the use of mechanisms which are extensible to multiple problem domains and underlying infrastructural technologies which can support broader enterprise issues. Information technologies spur the need for information interface solutions (e.g., opportunities for virtual enterprises) but can also be applied in the development of those solutions (e.g., network-based collaborations). Information technology has helped the Program's participants better communicate among themselves and with their industrial counterparts. The Program has progressed from physical, proximal solutions like the installation of a shared laboratory facility, to the dissemination of programmatic information via internal and external networks, to the use of the internet as the means for directly accessing technology solutions such as testing services and standard reference datasets, and now onto the development of a virtual manufacturing collaboratory. Each incremental improvement resulting from the application of information technology to the Program's work brings with it a new set of challenges because the new capabilities give us the vantage point of being able to see what's attainable next. This phenomenon parallels the situation in the application of information technology to the product realization process itself, in that new technology applications allow for new capabilities which in turn incur another set of information interface issues. With no lack of new information interface issues to address, SIMA is positioned to respond to new challenges as appropriate to its resources and according to industry's agenda by using information technologies to their best advantage. 


\section{References}

[1] “Technical Program Description Systems Integration for Manufacturing," Bloom, H., NISTIR 5476, NIST, Gaithersburg, MD, July 1994.

[2] "High Performance Computing and Communications: Toward a National Information Infrastructure," Report by the Committee on Physical, Mathematical, and Engineering Sciences, Federal Coordinating Council for Science, Engineering, and Technology, Office of Science and Technology Policy, published by the National Coordination Office for HPCC, 1994.

[3] "Information Infrastructure Technology and Applications," Report of the IITA Task Group, High Performance Computing, Communications and Information Technology Subcommittee, Federal Coordinating Council for Science, Engineering, and Technology, Office of Science and Technology Policy, published by the National Coordination Office for HPCC, February 1994.

[4] "HPCC FY95 Implementation Plan," Office of Science and Technology Policy, published by the National Coordination Office for HPCC, April 1994.

[5] "High Performance Computing and Communications: Advancing the Frontiers of Information Technology," Report by the Committee on Computing, Information, and Communications, National Science and Technology Council, published by the National Coordination Office for Computing, Information, and Communications, 1996.

[6] "SIMA Reference Architecture Part 1: Activity Models," Barkmeyer, E., ed., NISTIR 5939, NIST, Gaithersburg, MD, December 1996.

[7] "Transmission Control Protocol," Postel, J. ed., RFC-793, Internet Engineering Task Force, September 1981.

[8] “Internet Protocol," Postel, J. ed., RFC-791, Internet Engineering Task Force, September 1981.

[9] "Hypertext Markup Language - 2.0," Berners-Lee, T., Connolly, D., RFC-1866, Internet Engineering Task Force, November 1995.

[10] "Hypertext Transfer Protocol -- HTTP/1.0", Berners-Lee, T, et al., RFC-1945, Internet Engineering Task Force, May 1996.

[11] "Uniform Resource Locators," Berners-Lee, T, et al., RFC-1738, Internet Engineering Task Force, December 1994.

[12] "Background Study - Requisite Elements, Rationale, and Technology Overview for the Systems Integration for Manufacturing Applications (SIMA) Program," Barkmeyer, E., et al., NISTIR 5662, NIST, Gaithersburg, MD, September 1995.

[13] "Initial Manufacturing Exchange Specification (IMES) Concept Document For Manufacturing Systems Integration," Kemmerer, S., Fowler, J., ed., NISTIR 5978, NIST, Gaithersburg, MD, February 1997.

[14] "Systems Integration for Manufacturing Applications Program 1995 Annual Report," Fowler, J., Luce, M., NISTIR 5839, NIST, Gaithersburg, MD, May 1996.

[15] "Configuration-controlled 3 dimensional design," ISO 10303-203, International Organization for Standardization, Geneva, Switzerland. 


\section{Manufacturing Systems Environment (MSE) Projects}

Projects in this category develop integration technologies and standards in support of a broad range of industrial manufacturing domains that include mechanical products, electronics, construction, and chemical processing. The application systems of interest within these domains include design (product, process, and enterprise), planning, scheduling, process modeling, shop control, simulation, inspection, assembly, and machining. The problem scope includes manufacturing systems integration both within and among multiple enterprises. The MSE projects focus on the development of infrastructure technologies, interface protocols, and information models with the intention of applying these integration solutions to application system incompatibilities. Typical integration and interface technology solutions include information protocols for product and process data, information repositories, and frameworks. The major result of MSE activities are integration specifications for manufacturing systems and prototype process models for use throughout the manufacturing environment.

\section{[MSE1] Electronic Commerce of Component Information (ECCI)}

Project Manager: James St. Pierre

Telephone: (301) 975 - 4124

E-mail: james.st.pierre@nist.gov

Summary Description: The objective of this project is to actively contribute to the technical development of neutral product data exchange specifications and component information infrastructure for the electronics industry. Towards this goal the project works to resolve conflicts among competing and conflicting standardization efforts within the electronics industry. ECCI staff work with industry and other government laboratories to promote the transfer of technical information between the manufacturers of electronic parts and those who need parts for the design, manufacture, and repair of electronic systems. The scope of work includes research, development of prototype solutions, and information specification development.

\section{[MSE2] Information Protocols for Design}

Project Manager: Ram Sriram

Telephone: (301) 975 - 3507

E-mail: ram.sriram@nist.gov

Summary Description: The objective of this project is to develop standards and protocols enabling interoperability among design applications and between design applications and other engineering applications, such as process planning and production engineering. ISO 10303 ("STEP") has been focusing on developing various protocols for exchanging product data. However, STEP does not fully address the advanced information exchange requirements necessitated by leading-edge CAD and CAM systems. Further, emergence of new computer-based design support systems will introduce additional interoperability issues. This project aims to extend STEP and related standards to address the above problems. The focus will be on design content and knowledge/design rationale representation. Specific tasks address constraint and feature-based information (parametric representations), a solid interchange format for rapid prototyping machines, engineering ontologies, design and process planning interfaces, and interfaces between virtual reality-based $C A D$ and traditional $C A D$ systems. 
SIMA Projects

\section{[MSE3] Framework}

Project Manager: Neil Christopher

Telephone: (301) 975 - 3888

E-mail: neil.christopher@nist.gov

Summary Description: The objective of this project is to analyze, implement, validate, and report on standards and pre-normative specifications developed by industry. This project performs detailed analyses of industry developed specifications as they apply to manufacturing systems integration. Validation testing of these specifications against manufacturing operations in NIST's laboratory setting will be performed. The installation of an object oriented communications infrastructure for use by the other projects of the SIMA MSE program will be completed. The project will also work to develop a framework of specifications based on enterprise integration modeling requirements emerging from ISO TC184 /SC5 / WG1.

\section{[MSE4] Manufacturing Enterprise Integration}

Project Manager: Jim Nell Telephone: (301) 975 - 5748

E-mail: jim.nell@ nist.gov

Summary Description: Manufacturing enterprises are seeking ways to improve their infrastructure and processes to enable more effective operation in a more agile, virtual-enterprise mode. The investment justification for doing this varies by specific company, but reasons focus upon higher quality products, better repeatability, lower cycle time, and more customized production capability. Re-engineering should not occur in a vacuum. There should be careful analysis to define the total domain of enterprise representation. Also needed is a guideline regarding how to subdivide the domain logically. This project will define a scenario for representing an enterprise according to a framework, an architecture, and models. The project will also address life cycles of enterprises and models. The program will identify what, of the above, should be standardized. Much work is being done on this challenge by consortia around the world. This project will coordinate the work to the extent that existing groups and groups planning to work a sector of the domain are able to identify what has or is being done so that they can leverage their work.

\section{[MSE5] Operator Interfaces for Virtual and Distributed Manufacturing}

Project Manager: Ernie Kent

Telephone: (301) 975 - 3460

E-mail: ernest.kent@nist.gov

Summary Description: The objective of this project is to develop interface specifications enabling monitoring and control of geographically distributed manufacturing systems. The operator interface to such manufacturing systems are virtual renditions of the processes being monitored and controlled. The operator interface specifications resulting from this project will be based on methods for collecting and presenting information required to interact with remote manufacturing systems via wide-area networks. 


\section{[MSE6] Process Planning Applications}

Project Manager: Shaw Feng

Telephone: (301) 975 - 3551

E-mail: shaw.feng@nist.gov

Summary Description: The objective of this project is to develop and test information specifications enabling integration of various manufacturing applications with process planning systems. There are two principal areas of work in the project. The first is to define a preliminary framework of open interface specifications for collaborative design and process planning. This framework incorporates the draft ISO 10303 ("STEP") application protocol for feature-based design and process planning ("AP224"), a message model, and a process planning application programming interface. The second principal area of work is to test, validate, improve, and advance the draft STEP application protocol for process plans for numerical controlled (NC) machining ("AP213") to international standard status. As part of this effort, testing of the AP213 specification will be performed through pilot implementations with process planning and NC programming systems vendors.

\section{[MSE7] Process Plant Engineering and Construction}

\section{Project Manager: Kent Reed}

Telephone: (301) 975 - 5852

E-mail: kent.reed@nist.gov

Summary Description: The objective of this project is to work with U.S. industry to develop a technical capability to represent and exchange information supporting the design and construction of structural systems using internationally accepted protocols. The U.S. construction industry seeks to improve its use of computerized systems through integration, e.g., automation of the exchange and sharing of information among systems. The evolving international standard ISO 10303 ("STEP") is providing the base technology. The U.S. structural engineering community has recognized the advantages of STEP and seeks to make STEP exchange viable in its computerized design, analysis, and fabrication systems.

\section{[MSE8] Production and Product Data Management}

\section{Project Manager: Chuck McLean}

Telephone: (301) 975 - 3511

E-mail: charles.mclean@nist.gov

Summary Description: The objective of this project is to develop models, interfaces, techniques, and prototypes for integrating production system engineering, production management, simulated production facilities, and product data management systems with each other and with other manufacturing applications and support systems. This project has three sub-projects: 1) integration of production management systems; 2) integration of production system engineering applications (e.g., plant layout with manufacturing simulation); and 3) integration of product data management with other manufacturing applications. As part of the production management subproject, the focus will be on: 1) validation, consensus building, and technology transfer of an information model and messaging specification, and 2) the development of additional specifications for work orders, routings, schedules, and dispatch lists. As part of the production system engineering subproject, the focus will be on: 1) development of a plant layout to simulation interface, and 2) developing the assembly process specification to simulation interface. The product data management subproject will focus on the development of an interface to product data management systems to support version control, authorization, references, engineering change orders and document management states. 
SIMA Projects

\section{[MSE9] Rapid Response Manufacturing}

Project Manager: Kevin Jurrens

Telephone: (301) 975 - 5486

E-mail: jurrens@nist.gov

Summary Description: The objective of this project is to facilitate standardization and implementation of a proposed electronic representation for manufacturing resource data. The representation will cover a limited scope of manufacturing resource data, including milling and turning machine tools; cutting tools appropriate to the processes of milling, drilling, boring, reaming, tapping, and turning; cutting tool inserts; and the tool holding and assembly components required to mount the cutting tools to the machines. ISO and ANSI standardization efforts for cutting tool data have been initiated with NIST staff serving in key roles. Industrial collaborations have been formed to review and implement the manufacturing resource data structure.

\section{[MSE10] Reference Model Architecture}

Project Manager: Harry Scott

Telephone: (301) $975-3437$

E-mail: harry.scott@nist.gov

Summary Description: The objective of this project is to develop a reference model architecture for intelligent control of manufacturing processes. Further, the project will demonstrate, validate and evaluate the reference model architecture through analysis and performance measurements of a simulated and prototype implementation. A first implementation of the architecture uses an inspection workstation facility as a testbed. This project builds on the work to date in examining and understanding alternative architectural approaches and required functionality for implementing intelligent control systems in the manufacturing domain. In particular, the architecture will bring together multiple manufacturing system architectural elements under a single consistent reference specification with standard interfaces developed or adopted for communication between architectural components.

\section{[MSE11] STEP Application Protocols for Polymers Test Data}

Project Manager: Joe Carpenter

Telephone: (301) 975 - 6397

E-mail: joseph.carpenter@nist.gov

Summary Description: The objective of this project is the development of a formal ISO standard for exchanging data generated by polymers testing. Other existing or developing standards provide prototype tests of the exchange of materials information in a superficial way (mostly a material's name, specification, and limited properties); they do not provide the details of the data resulting from materials testing. Specifically the project intends to work in conjunction with industry to develop an ISO 10303 specification (i.e., an application protocol) aimed at handling polymer test data collected according to industry-adopted methodologies.

\section{[MSE12] STEP for the Process Plant Industry}

Project Manager: Mark Palmer

Telephone: (301) 975 - 5858

E-mail: mark.palmer@ nist.gov

Summary Description: The objective of this project is to work with U.S. industry to develop, test, and demonstrate a coordinated suite of ISO 10303 ("STEP") application protocols that meet the information needs of the process plant industries. The U.S. process plant industries 
seek to improve their use of computerized systems through integration of information systems, e.g., automation of the exchange and sharing of information among systems. The many computerized systems in use can be integrated only at great cost because of their incompatible proprietary representations for information. Standard, neutral information representations and exchange methods are needed that allow system vendors to be innovative and yet allow system users to exchange and share information about process plants coherently. In NIST workshops and industry meetings, owners, engineers and constructors, information technology providers, and parts suppliers identified the design and fabrication of plant piping systems and the delivery of process engineering information as top priorities for application protocol development. Starting with these requirements, industry and NIST are working to develop these specifications and to participate in the development of other application protocols needed by the process plant industries.

\title{
[MSE13] Supply Chain Integration
}

\author{
Project Manager: Mary Beth Algeo \\ Telephone: (301) 975 - 2888 \\ E-mail:mary.algeo@nist.gov
}

Summary Description: The objective of this project is to identify potential information exchange and interface protocol solutions in order to improve supply chain integration. Supply chain integration equates to getting the right information to the right people in the supply chain at the right time, thereby achieving equilibrium between supply and demand. An optimized supply chain is one which moves a product from the point-of-origin to that of consumption in the least amount of time and at the smallest cost. The thrust of this project is to develop a broad understanding of supply chain integration and its implications on manufacturing systems. This project will provide an overall view of supply chain integration and will seek to identify those technology and standards gaps which could be addressed in future work.

\section{[MSE14] Unified Process Specification Language}

Project Manager: Amy Knutilla

Telephone: (301) 975 - 3514

E-mail: amy.knutilla@ nist.gov

Summary Description: The objective of this project is to identify or create a process representation that is common to all manufacturing applications, generic enough to be decoupled from any given application, and robust enough to be able to represent process information for any given application. This project is designed specifically to promote outreach and consensus through activities such as the establishment of electronic discussion lists, active industry review and feedback, and on-line project status through the World Wide Web.

\section{[MSE15] Virtual Environments and Visualization for Manufacturing}

Project Manager: Sandy Ressler

Telephone: (301) 975 - 3549

E-mail: sressler@nist.gov

Summary Description: The objective of this project is to create new visualization environments which assists the manufacturing industry in achieving systems integration of manufacturing applications. This is being accomplished by enhancing several SIMA applications through Virtual Environment (VE) technology of several kinds. Current limitations of both immersive and non-immersive VE technology are being examined. VE standards which will enhance the manufacturing process are being investigated as well. In addition to "traditional" VE using 
a computer generated polygonal environment, image based VEs are being explored. Existing proprietary software tools are being used as mechanism to create portable interoperable environments using non-proprietary standard representations such as Virtual Reality Modeling Language (VRML). Finally, the introduction of virtual humans into the factory floor will enhance the dying practice of ergonomic and human motion time studies, a necessary factor in the design of production spaces.

\section{Standards Development Environment (SDE)}

Projects in this category assist industry in implementing voluntary consensus standards relevant to computer integrated manufacturing (CIM), facilitate industry efforts to test evolving information exchange and interface specifications utilizing internet technology, and accelerate industry deployment of consensus standards. There is a general theme of providing effective support environments for the development of standards as well as facilitating the harmonization across the broad spectrum of standards that compose the range of information and supporting technology required for enterprise integration.

\section{[SDE1] Application Protocol Development Environment}

Project Manager: Lisa Phillips

Telephone: (301) 975 - 5021

E-mail: lisa.phillips@nist.gov

Summary Description: The objective of this project is to accelerate the development of the ISO 10303 ("STEP") suite of standards by aiding application protocol (AP) developers in creating AP specifications more efficiently, with higher quality and at a lower cost. Current practices for AP development require extraordinary labor expenditures on behalf of developers to define the requirements and document the required technical elements. An integrated suite of software tools will be established to assist STEP AP development. These software tools will use an information registry at NIST consisting of STEP and STEP-related documents and data. Documents will be represented in the Standard Generalized Mark-up Language (SGML) to enable "intelligent" access to any aspect of STEP documents and better transferability among differing computer platforms. The AP development process includes defining information requirements, modeling that information, verifying that the information models are correct, identifying how these requirements are satisfied by STEP core concepts, developing test criteria for implementations, and documenting all components in a mandated format. An integrated toolset will be provided to support each of these process steps.

\section{[SDE2] Protocol Testing for Process Plant Representations}

Project Manager: Kent Reed

Telephone: (301) 975 - 5852

E-mail: kent.reed@nist.gov

Summary Description: The objective of this project is to support the companion projects "STEP for the Process Plant Industries" and "Process Plant Engineering and Construction" by maintaining a computing infrastructure supporting the integration activities of the projects' industrial partners. The computing infrastructure provides a baseline of industrial practice in process plant engineering and construction software applications. Repositories of specifications, test cases, data, and the like will be maintained and available to project partners. 


\section{[SDE3] STEP Conformance Testing}

Project Manager: Mary Mitchell

Telephone: (301) 975 - 3538

E-mail: mary.mitchell@nist.gov

Summary Description: The objective of this project is to provide an objective basis for assessing the conformance of a software product to the ISO 10303 standard ("STEP") which includes: providing a test system that is extensible to the scope of STEP; supporting tools that aid the development of abstract test suites; providing testing tools for use by STEP implementors, e.g. CAD and PDM vendors; and gaining international consensus on test suites/test methods/procedures for use in software validation. But the US requirements for a STEP testing capability into the year 2000 go well beyond this. To maintain this momentum, the direction of conformance testing must evolve to match that of STEP. The specification and use of STEP is advancing in two directions: from product model exchange to transaction based access of a shared repository (from Part 21 to Part 22: SDAI); from the use of a single Application Protocol to a compatible series of APs which interoperate together to support the entire product life cycle. This requires the evolution of testing capability that is developed in parallel such that: a testing process, test methods and tools are available for SDAI testing; and a testing process, test methods and tools are available for the assessment of implementations supporting more than one AP. Further, improved methods and tools are needed to support more efficient interoperability testing, and a self-sustaining testing program needs to be put in place to support industry's demand for software certification.

\section{[SDE4] STEP Implementation Prototypes}

Project Manager: Simon Frechette

Telephone: (301) 975 - 3335

E-mail: simon.frechette@nist.gov

Summary Description: The objective of this project is to accelerate the adoption and near term production implementation of ISO 10303 ("STEP") in industry. The SIP project will promote the development of industry consensus on "best practices" for product data communication, integrate and apply current software tools, and provide training on STEP related technologies. The SIP project will work to ensure the STEP standard is responsive to the product data needs of U.S. industry. NIST will assist the Automotive Industry Action Group (AIAG) in determining requirements and preparing STEP implementations for production-ready applications in the automotive supplier chain. The project will target product data exchange for Computer Aided Design (CAD) and Configuration Management (CM). This data will be used for various design and manufacturing applications, however the project will focus on data required for packaging, numerical control, and configuration management.

\section{Testbeds and Technology Transfer Environment (TTTE)}

Projects in this category develop technology transfer infrastructure which can be used to exchange manufacturing information using internet technology, to develop prototype information services in collaboration with industry partners which could become commercialized products, to develop services related to document searches and retrieval of government and other research reports, and to establish communication channels for network of researchers and implementors of manufacturing technologies. Testbeds developed under the auspices of TTTE are intended to serve as collaborative testing and demonstration sites as well as to serve as the focal points for information dissemination. 
SIMA Projects

\section{[TTTE1] Advanced Manufacturing Systems and Networking Testbed (AMSANT)}

Project Manager: Rob Densock

Telephone: (301) 975 - 6546

E-mail: densock@nist.gov

Summary Description: The objective of this project is to provide a distributed, multinode facility at NIST that will enable collaborative development of specifications enabling manufacturing systems integration using an advanced computing and communications infrastructure. Facilities developed under the auspices of this project support the computing, communications, and other operational aspects of the technical projects. The project continues to supports the needs of the other technical projects through annual assessments of platform and software requirements, infrastructure enhancements, and network management.

\section{[TTTE2] Analysis Tools for Assessment and Optimization of Product and Process Design}

Project Manager: Jim Filliben

Telephone: (301) 975 - 2855

E-mail: james.filliben@ nist.gov

Summary Description: The objective of this project is to develop an integrated internet-accessible environment for accessing a state-of-the-art, literature-based statistical methodology. The environment to be developed will allow users to translate engineering problems to their statistical analogues as well as to identify and apply appropriate statistical tools to a wide spectrum of commonly encountered manufacturing process/product problems.

\section{[TTTE3] Green's Function Library for Advanced Materials Applications with Internet Access}

Project Manager: Vinod Tewary

Telephone: (303) 497-5753

E-mail: vinod.tewary@nist.gov

Summary Description: The objective of this project is to develop an interactive tool available over the world wide web (WWW) for using Green's function and boundary element methods to facilitate the design, inspection, and manufacture of components made with advanced materials. The idea is to identify, (pre)compute, and save generic, repeatedly-useful items, called discretized region-dependent Green's functions, when modeling difficult physical problems by computer. With a library of such functions, a designer need not have the expertise of the computational engineer and need not wait for lengthy computations, often done on very large computers by specialists. Such computations are usually based on resources and modeling effort a designer either cannot or would rather not expend. In short, with the library and today's technology, the fruits of modeling effort and heavy computation by computational experts may be stored and speedily used repeatedly by non-experts. As we enter the era of advanced materials, the Green's functions library will be even more useful. Many advanced materials are anisotropic and thus cannot be efficiently analyzed using conventional mathematical approaches. Powerful mathematical techniques have been developed at NIST for calculating the anisotropic Green's functions. The library will be widely applicable to a variety of problems in stress analysis, ultrasonics, and acoustics. With the main library tool available via the internet containing specialized depositories of pre-computed Green's functions for industry-specific components, the library will be a continuously developing tool. 


\section{[TTTE4] Integration of NIST Standard Reference Data into Information Networks}

Project Manager: Ed Saloman

Telephone: (301) 975 - 5554

E-mail: saloman@nist.gov

Summary Description: The objective of this project is to make NIST physics reference data available via the Web. The project has provided databases of values of fundamental physical constants; an atlas of uv lines from a Pt/Ne reference lamp (for uv calibration of spectrometers); critically evaluated NIST data on atomic energy levels, transition probabilities, and wavelengths; ir calibration tables (for ir calibration of spectrometers); critically evaluated transition frequencies for astronomically detected molecular transitions; $x$ ray attenuation in materials; and bibliographic databases of atomic transition probabilities and of photon total cross sections. Most of these databases have sophisticated interfaces which make them easy to use over the computer networks. By making these databases available via the internet, the intention is also to demonstrate a prototype framework providing access to a full range of scientific and engineering information including codes, standards, and regulatory information, numeric data, and graphical and pictorial information.

\section{[TTTE5] NIST Informatics Web Site Supporting Advanced Ceramics Applications}

Project Manager: Ed Begley

Telephone: (301) $975-6118$

E-mail: edwin.begley@nist.gov

Summary Description: The objective of this project is to establish a Web site for representing, archiving, accessing, manipulating, utilizing, and applying results stemming from advanced ceramics research at NIST. Initial work focused on the development of a prototype internetaccessible version of the NIST High Temperature Superconducting Materials Database ("WebHTS"). While continuing to develop WebHTS, the project focus will expand to include demonstrations of electronic collaboration and, also, the transfer of different types of information relevant to advanced ceramics manufacturing. One such effort will be in response to industry requests for a directory that will assist them with locating computerized and non-computerized sources of materials specific information. The project will transform NIST's published "A Guide to Locating and Accessing Computerized Numeric Materials Databases" into an internet accessible format to provide an effective forum for disseminating, maintaining, and expanding this guide. Another effort will focus on acoustic-based measurements for particle characterization and process control and will serve as the cornerstone for a future, more general treatment of powder processing and characterization information and research. A Web site will be developed for promoting meetings relevant to this area and for distributing information such as manuscript titles and abstracts, an executive summary, and proceedings. The site also may be used to distribute computational tools and application notes for electroacoustic measurements and can serve as a centralized repository of property data and measurement parameters targeted to support users of acoustic-based techniques. Additionally, access will be provided to technical and scientific information derived from on-site research activities in support of advanced ceramic powder processing. Finally a new effort will be initiated to capture expertise, via computer, enabling the interpretation and determination of phase equilibria diagrams. The "NIST Equilibria Expert" will include digital video and audio where appropriate, still images, animation, numeric information, and the expertise of NIST scientists whose primary research efforts are centered upon phase equilibria. 
SIMA Projects

\section{[TTTE6] NIST Manufacturing Collaboratory}

Project Manager: Michele Steves

Telephone: (301) 975 - 3537

E-mail: michelle.steves@nist.gov

Summary Description: The objective of this project is to develop a collaboratory which will ultimately enable individuals and groups of manufacturing researchers to tap into, as well as contribute to, the collective knowledge regarding advanced manufacturing research and standards in a coherent, unencumbered fashion. This project is approaching the development of a collaboratory for manufacturing through two complementary tracks. The first approach is to increase our knowledge about the special requirements of the manufacturing domain with regard to computer-mediated collaboration. This is accomplished by analyzing what has been achieved to-date of the topics at hand: human collaboration in the manufacturing domain and computer-mediated collaboration in general, and to apply that analysis to addressing the question of how can that knowledge be extended or generalized for applicability in the NIST Manufacturing Collaboratory. The second approach is to learn by designing and implementing a prototype collaborative environment and using that prototype to test collaborative applications and techniques. The environment will be analogous to a familiar, well-understood concept such as a conference. There will be seminars, meeting rooms, break-out sessions, all front-ended by a user-friendly, easy to navigate, virtual environment. Underlying collaborative applications will "plug-in" to the environment, providing flexible collaboration tool configurations.

\section{[TTTE7] Online Access to NIST Chemical Reference Data}

Project Manager: W. Gary Mallard

Telephone: (301) 975 - 2564

E-mail: gary.mallard@nist.gov

Summary Description: The objective for this project is to develop a robust method for accessing NIST chemical databases via the internet through a uniform method of specifying chemicals, including by means of chemical structure drawings. The project will expand the structure of this NIST Chemistry WebBook and customize the algorithms to support a wide variety of database software and contents and functions. Mechanisms will be explored for delivery of data to application software. Because every chemical database supports specification of a chemical, this tool - upon completion - will provide uniform access to all NIST chemical data.

\section{[TTTE8] Standards for Exchange of Instrument Data and NIST Chemical Reference Data}

Project Manager: Gary Kramer

Telephone: (301) $975-4132$

E-mail: gary.kramer@nist.gov

Summary Description: The objective of this project is to develop information models supporting data exchange standards in analytical chemistry for instrument-to-instrument, instrument-to-application, and application-to-application interchanges. Many critical decisions in manufacturing and engineering depend on reliable chemical data about materials and chemical reactions.

Often this information comes directly from instruments in chemical analysis laboratories. The thrust of this program component is to make standard reference data in analytical chemistry data, especially data coming directly from instruments, more readily available to engineers and scientists in the U.S. manufacturing and industrial complex. Developing standard formats for exchange of analytical chemistry data for the manufacturing and engineering segments of industry is critically important to take full advantage of new instrumentation capabilities. 
The following tables illustrate at a very high level some of the achievements planned for the SIMA Program during the next two years.

\begin{tabular}{|c|c|c|c|}
\hline Year & $\begin{array}{c}\text { Manufacturing System } \\
\text { Environment }\end{array}$ & $\begin{array}{c}\text { Standards Development } \\
\text { Environment }\end{array}$ & $\begin{array}{l}\text { Testbeds \& Technology } \\
\text { Transfer Environment }\end{array}$ \\
\hline FY97 & $\begin{array}{l}\text { Demonstrate initial prototype } \\
\text { integration of computer-aided } \\
\text { design and virtual assembly } \\
\text { applications. } \\
\text { Conduct series of workshops on } \\
\text { Enterprise Integration Frame- } \\
\text { works and submit resulting } \\
\text { model for voluntary standardiza- } \\
\text { tion. } \\
\text { Submit specifications resulting } \\
\text { from development of prototypes } \\
\text { for product data management } \\
\text { integration, parametric feature- } \\
\text { based design, and manufacturing } \\
\text { resource integration for volun- } \\
\text { tary standardization. } \\
\text { Develop initial model for repre- } \\
\text { sentation of process capabilities } \\
\text { enabling integration of plan- } \\
\text { ning, simulation, and other man- } \\
\text { ufacturing applications. } \\
\text { Develop initial models and spec- } \\
\text { ifications enabling integration of } \\
\text { production system engineering } \\
\text { and production system simula- } \\
\text { tion. } \\
\text { Develop initial model for } \\
\text { exchange of analytical chemistry } \\
\text { information among chemical } \\
\text { design and analysis systems. } \\
\text { Develop initial models and spec- } \\
\text { ifications enabling integration of } \\
\text { process planning, shop floor } \\
\text { scheduling, and shop floor data } \\
\text { collection. } \\
\text { Demonstrate behavior-enhanced } \\
\text { virtual reality interfaces to pro- } \\
\text { duction system simulations. }\end{array}$ & $\begin{array}{l}\text { Develop metrics and evaluations } \\
\text { assessing usability/reliability of } \\
\text { STEP data exchange protocol } \\
\text { deployments in industrial pilot } \\
\text { implementations. } \\
\text { Develop test specifications } \\
\text { enabling conformance testing of } \\
\text { data exchange protocols for } \\
\text { plant spatial configuration, asso- } \\
\text { ciative drafting, and process } \\
\text { planning/NC programming. } \\
\text { Develop test specification } \\
\text { enabling conformance testing of } \\
\text { interface protocol implementa- } \\
\text { tions based on the data access } \\
\text { interface for STEP. }\end{array}$ & $\begin{array}{l}\text { Develop initial collaboratory } \\
\text { environment supporting develop- } \\
\text { ment and validation of manufac- } \\
\text { turing integration specifications. } \\
\text { Provide prototype Web access to } \\
\text { statistical solutions for engineer- } \\
\text { ing product/process design prob- } \\
\text { lems. } \\
\text { Expand scope of scientific and } \\
\text { engineering reference data avail- } \\
\text { able via Web with provision of } \\
\text { additional physical, chemical, } \\
\text { and material data. }\end{array}$ \\
\hline
\end{tabular}




\begin{tabular}{|c|c|c|c|}
\hline Year & $\begin{array}{c}\text { Manufacturing System } \\
\text { Environment }\end{array}$ & $\begin{array}{c}\text { Standards Development } \\
\text { Environment }\end{array}$ & $\begin{array}{l}\text { Testbeds \& Technology } \\
\text { Transfer Environment }\end{array}$ \\
\hline FY98 & $\begin{array}{l}\text { Submit specifications resulting } \\
\text { from development of integration } \\
\text { prototypes for inspection sys- } \\
\text { tems for voluntary standardiza- } \\
\text { tion. } \\
\text { Submit specifications resulting } \\
\text { from prototype design and vir- } \\
\text { tual assembly integration for vol- } \\
\text { untary standardization. } \\
\text { Demonstrate remote operator } \\
\text { interfaces for machine and pro- } \\
\text { duction system monitoring and } \\
\text { control. } \\
\text { Demonstrate intelligent systems } \\
\text { architecture for manufacturing } \\
\text { system and machine control in } \\
\text { AMSANT facilities. } \\
\text { Demonstrate distributed design, } \\
\text { planning, and production appli- } \\
\text { cation integration using object- } \\
\text { based interfaces in AMSANT } \\
\text { and remote partner facilities. } \\
\text { Demonstrate integration of plan- } \\
\text { ning and simulation applications } \\
\text { using process data models. }\end{array}$ & $\begin{array}{l}\text { Implement conformance testing } \\
\text { systems/services for electrical } \\
\text { product data exchange protocols. }\end{array}$ & $\begin{array}{l}\text { Develop interface protocols } \\
\text { enabling integration of Web- } \\
\text { based scientific and engineering } \\
\text { reference data with manufactur- } \\
\text { ing applications and processes. } \\
\text { Demonstrate collaboratory envi- } \\
\text { ronment use by government and } \\
\text { industry partners in development } \\
\text { and validation of manufacturing } \\
\text { integration specifications. }\end{array}$ \\
\hline
\end{tabular}


